\title{
Scaling Transformation in the Rembrandt Technique Examination of the Progression Factors
}

\section{Barfod, Michael Bruhn; Leleur, Steen}

\section{Published in:}

International Journal of Information Technology and Decision Making

Link to article, DOI:

10.1142/S0219622013400014

Publication date:

2013

Document Version

Early version, also known as pre-print

Link back to DTU Orbit

Citation (APA):

Barfod, M. B., \& Leleur, S. (2013). Scaling Transformation in the Rembrandt Technique: Examination of the Progression Factors. International Journal of Information Technology and Decision Making, 12(5), 887-903. https://doi.org/10.1142/S0219622013400014

\section{General rights}

Copyright and moral rights for the publications made accessible in the public portal are retained by the authors and/or other copyright owners and it is a condition of accessing publications that users recognise and abide by the legal requirements associated with these rights.

- Users may download and print one copy of any publication from the public portal for the purpose of private study or research.

- You may not further distribute the material or use it for any profit-making activity or commercial gain

- You may freely distribute the URL identifying the publication in the public portal 


\title{
SCALING TRANSFORMATION IN THE REMBRANDT TECHNIQUE: EXAMINATION OF THE PROGRESSION FACTORS
}

\author{
MICHAEL BRUHN BARFOD \\ Department of Transport \\ Technical University of Denmark \\ Bygningstorvet 115, DK-2800 Kgs. Lyngby, Denmark \\ mbb@transport.dtu.dk \\ STEEN LELEUR \\ Department of Transpor \\ Technical University of Denmark \\ Bygningstorvet 115, DK-2800 Kgs. Lyngby, Denmark \\ sl@transport.dtu.dk
}

\begin{abstract}
This paper examines a decision support system (DSS) for the appraisal of complex decision problems using multi-criteria decision analysis (MCDA). The DSS makes use of a structured hierarchical approach featuring the multiplicative AHP also known as the REMBRANDT technique. The paper addresses the influence of the progression factor used when transforming the decisionmakers verbal responses from a semantic to a geometric scale using the technique. Conventionally, the progression factor 2 is used for calculating scores of alternatives and $\sqrt{2}$ for calculation of criteria weights. Tests are conducted on the magnitude of these progression factors in order to examine the sensitivity towards the final outcome of an analysis. For illustration a case study dealing with the appraisal task of a large transport infrastructure project is presented. Finally, conclusions are drawn and perspectives are set out in the context of the proposed DSS and its use for strategic decision making.
\end{abstract}

Keywords: Multi-Criteria Decision Analysis; Decision Support Systems; AHP; REMBRANDT.

\section{Introduction}

This paper examines a decision support system (DSS) for the appraisal of complex transport infrastructure decision problems using multi-criteria decision analysis (MCDA). The DSS makes use of a structured hierarchical approach featuring the multiplicative AHP also known as the REMBRANDT technique. The technique is a further development of the original AHP and it proposes to overcome three issues regarding the theory behind AHP namely by using direct rating on a geometric scale, the geometric mean method, and aggregation of scores by the product of alternative relative scores weighted by the power of weights obtained from analysis of the hierarchical elements above the alternatives. The aim of this paper is mainly to address the first issue regarding the direct rating on a geometric scale.

* Corresponding author. 
More specifically, the paper addresses the influence of the progression factors used when transforming the decision-makers' verbal responses from the semantic to the geometric scale. The REMBRANDT technique uses the progression factor 2 for calculating scores of alternatives and $\sqrt{2}$ for calculation of criteria weights, where the reason behind a lower progression factor for criteria may link to implicit trade-off considerations being more deliberate with criteria than is the case with scoring of alternatives. Tests will be conducted on the magnitude of the progression factors in order to examine the sensitivity towards the final outcome of an analysis.

For illustration of the DSS and the sensitivity calculations a case study dealing with the appraisal task of a large transport infrastructure project is presented. The scope of the case study is to identify the most attractive alternative for a new bridge or tunnel connection between the cities of Elsinore (Helsingor) in Denmark and Helsingborg in Sweden, which is supposed to take over both person and freight transport from the existing ferries and relieve the existing fixed link between Copenhagen in Denmark and Malmo in Sweden. The appraisal will make use of previously conducted cost-benefit calculations and descriptions of strategic issues. Finally, conclusions are drawn and research issues defining future work are set out in the context of the proposed DSS and its use for strategic decision making.

This paper is disposed as follows: After this introduction Section 2 introduces the case study used for illuminating the test calculations. Section 3 contains a description of the the REMBRANDT technique (the multiplicative AHP) and presents more closely the scaling issues of the progression factors used for transformations to the geometric scale. In Section 4 the REMBRANDT technique is applied to the case study and sensitivity calculations are made based on the progression factors. The results of these calculations are subsequently discussed in Section 5 before Section 6 concludes and outlines perspectives for future work within the research area.

\section{The case study}

The Oresund fixed link connecting the greater area of Copenhagen with Malmo in Sweden opened in July 2000. Today, eleven years later, the railway line of the link is close to its capacity limit resulting in delays and discomfort for the travellers. The case of this paper concerns a new complementary fixed link between Denmark and Sweden between the cities of Elsinore (Helsingor) and Helsingborg. Regionally, the proposed connection is expected to create a substantial increase in trade, education and work related benefits. Ultimately it is expected that a fixed link with increased commuter traffic across the border will result in a common labour and residence market. In addition, the recent decision to construct the Fehmarn Belt fixed link between Denmark and Germany will increase the number of travellers from central Europe through Denmark to the rest of Scandinavia (Sweden, Norway and Finland). This means additional traffic to cross the Oresund. ${ }^{1}$

The case is normally referred to as the HH-connection, see Figure 1, and has been examined since the 1980s where the first alignment proposals were suggested. The 
opening of the Oresund fixed link between Copenhagen and Malmo, however, postponed the HH-connection but now its planning is recommenced. In Figure 1 the proposed new fixed link is shown located approximately $50 \mathrm{~km}$ north of the existing fixed link across Oresund.

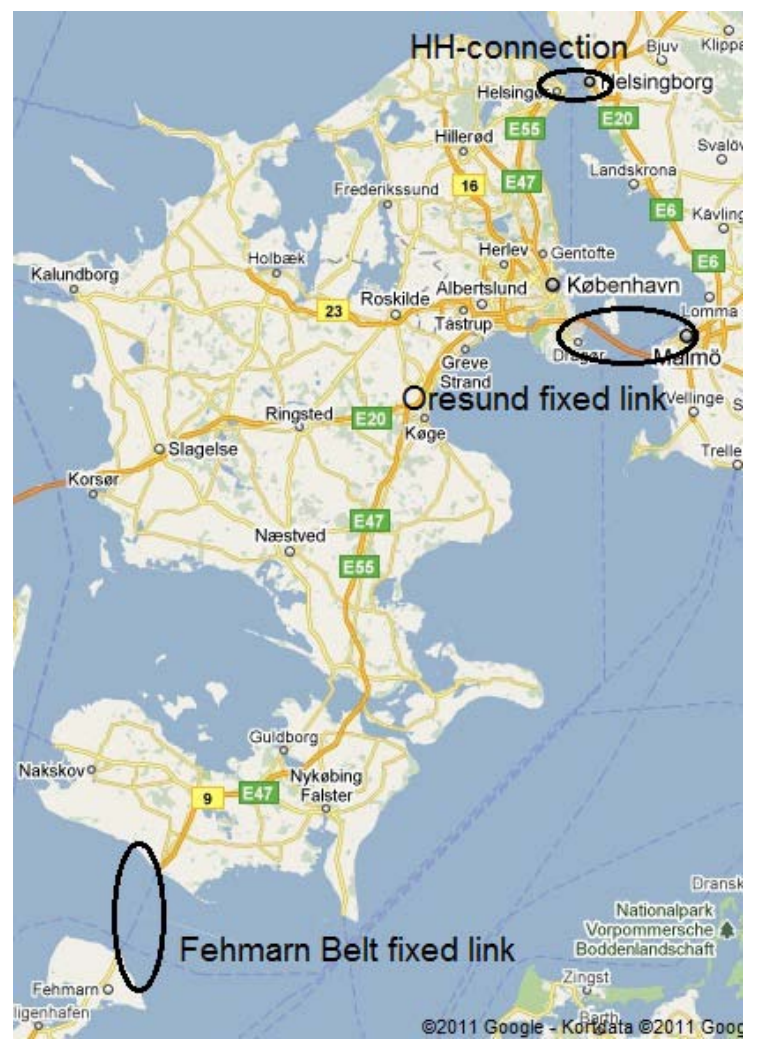

Figure 1. The proposed new fixed link (the HH-connection), the Oresund fixed link and the forthcoming Fehmarn belt fixed link (from Google maps)

The current situation with ferry service is referred to as the basis scenario where the proposed alternatives will substitute the ferries with a fixed link with four alternatives being considered, see Table 1.

Table 1. The four proposed alternatives for the HH-connection with construction costs in million DKK ${ }^{1}$

\begin{tabular}{llr}
\hline HH-connection & Description & Cost (mDKK) \\
\hline Alternative 1 (A1) & Tunnel for rail (2 tracks) person traffic only & 7,700 \\
Alternative 2 (A2) & Tunnel for rail (1 track) goods traffic only & 5,500 \\
Alternative 3 (A3) & Bridge for road and rail (2x2 lanes and 2 tracks) & 11,500 \\
Alternative 4 (A4) & Bridge for road (2x2 lanes) & 6,000 \\
\hline
\end{tabular}

Based on the Danish manual for socio-economic assessment ${ }^{2}$ the benefit-cost rates (BCR) shown in Table 2 have been determined applying transport modelling for road and rail. ${ }^{3}$ 
The reference scenario forecasting (RSF) technique ${ }^{4}$ is applied to the cost-benefit analysis in order to produce certainty graphs describing the alternatives' probability for being economic feasible if uncertainties are introduced to the assessment. The calculations are carried out by applying Monte Carlo simulation to the cost-benefit analysis using estimated RSF distributions (Erlang and Beta-Pert distributions for construction costs and time savings respectively). Based on this it is possible to calculate certainty values (CV), see Table 2, which are describing the probability for the alternatives being feasible.

Table 2. BCRs for the four alternatives

\begin{tabular}{lcc}
\hline Alternatives & BCR & CV \\
\hline A1 & 1.51 & $97 \%$ \\
A2 & 0.18 & $10 \%$ \\
A3 & 2.72 & $123 \%$ \\
A4 & 3.09 & $157 \%$ \\
\hline
\end{tabular}

It should be noted that an alternative will obtain a CV $>100 \%$ if the simulation implies BCRs $>1$ in all cases. For CVs $>100 \%$ the certainty 'distance' above $100 \%$ is added to the value. Where the conventional BCR gives a deterministic point estimate of the feasibility, the CVs give a probability based interval estimate of how the two most important uncertainty factors can affect such a point estimate.

Due to the high influence on the further development of the Oresund region a wider set of decision criteria have been identified in addition to the CVs to lay the foundation for a comprehensive assessment of the four alternatives. Table 3 depicts the full criteriaset. ${ }^{1}$

Table 3. Assessment criteria

\begin{tabular}{ll}
\hline Criterion & Definition \\
\hline C1 & Impact on regional economics \\
C2 & Impact on ecology in sound \\
C3 & Impact on transport network and accessibility \\
C4 & Impact on towns \\
C5 & Robustness of feasibility (CVs) \\
\hline
\end{tabular}

The alternatives are in Section 4 assessed under the criteria using the multiplicative AHP also known as the REMBRANDT technique, which is described in the following Section 3.

\section{The REMBRANDT technique (multiplicative AHP)}

The original $\mathrm{AHP}^{5,6}$ by Saaty has been criticised for various reasons: 1) for the fundamental scale to quantify human judgments; 2) as it estimates the impacts scores of the alternatives by the Perron-Frobenius eigenvector; and 3) as it calculates the final scores of the alternatives using the arithmetic-mean aggregation rule. These controversial issues are well-known and not new. Already Zahedi ${ }^{7}$ signalised that the criticism of the 
AHP concentrated on the estimation of the impact scores, but that no major controversy existed concerning the aggregation step. Criticism of the fundamental scale was not mentioned by Zahedi, but Belton ${ }^{8}$ brought forward several arguments against the scale and the aggregation rule. Later also Stewart ${ }^{9}$ discussed the above issues and warned that the AHP, despite its widespread popularity, should be used with considerable caution. More recently Korhonen and Topdagi ${ }^{10}$ have also brought forward arguments regarding the inappropriateness of the ratio scale in specific decision situations. Barzilai et al. ${ }^{11}$, Barzilai and Golani ${ }^{12}$ and Barzilai ${ }^{13}$ observed that the AHP, since it is initially based upon ratio information, should be converted into a variant with a multiplicative structure.

A multiplicative version of the original AHP is available in form of the so-called REMBRANDT (Ratio Estimations in Magnitudes or deci-Bells to Rate Alternatives which are Non-DominaTed technique), see Lootsma ${ }^{14}$, Olson et al. ${ }^{15}$ and Ramanathan. ${ }^{16}$ As for the original AHP the REMBRANDT technique makes use of a structured hierarchical approach based on the principle that decision-makers make pair wise comparisons between alternatives to determine subjective impacts under each criterion in the assessment and between criteria in order to determine their relative importance. Finally, aggregating the results leads to a final score for each project, which allows a subjective rank ordering of the projects.

The systematic pair wise comparison approach is one of the cornerstones of the REMBRANDT technique. ${ }^{14}$ REMBRANDT makes use of a procedure for direct rating which requires the decision-makers to consider all possible pairs of alternatives with respect to each criterion in turn in order to determine which one of the projects in the pair is preferred and to specify the strength of preference according to a semantic scale (associated a numeric 0-8 scale). The approach is as mentioned a multiplicative development of the AHP and it proposes to overcome the three issues regarding the theory behind AHP.

First, the direct rating in REMBRANDT is on a geometric scale ${ }^{14}$ which replaces Saaty's $1-9$ original scale. Second, the eigenvector method originally used in AHP is replaced by the geometric mean method, which avoids potential rank reversal. ${ }^{11}$ Third, the aggregation of scores by arithmetic mean is replaced by the product of alternative relative scores weighted by the power of weights obtained from analysis of the hierarchical elements above the alternatives. ${ }^{17}$

In the use of the REMBRANDT technique in this paper it is assumed that the ratifying group consists of $g$ decision-makers $(g \geq 1)$, and that at any stage of the process there are $n$ alternatives $(n \geq 1)$ under consideration. At the first evaluation level of the analysis, each pair of alternatives $A_{j}$ and $A_{k}$ is presented to the decision-makers under a specific criterion. The decision-makers are then asked to express their graded comparative judgment about them. That is, the decision-makers express their indifference between the two, or a weak, definite, strong or very strong preference for one project over the other. Thus, at this stage the decision-makers are asked to make as standard $n(n-1) / 2$ pair wise comparisons. Indeed only (n-1) properly chosen comparisons would be sufficient, for which reason the standard leads to much more information being collected 
than actually needed. ${ }^{18}$ Such redundancy, however, is usually beneficial as it enables a smoothing of the results of the analysis. Incomplete pair wise comparisons in a group of decision-makers are handled in a general way by using REMBRANDT, see Lootsma ${ }^{19}$ for details; the case of complete pair wise comparisons by each and every one of the decision-makers is a special case. In this context it is assumed that alternative $A_{j}$ and $A_{k}$ have the same subjective values $V_{j}$ and $V_{k}$ for all decision-makers in a group. Using the REMBRANDT technique the group's agreed upon judgment about the pair $A_{j}$ and $A_{k}$ is taken to be an estimate of the preference ratio $V_{j} / V_{k}$.

The decision-makers' pair wise comparative judgment of $A_{j}$ versus $A_{k}$ is captured on a category scale to frame the range of possible verbal responses. This is converted into an integer-valued gradation index $\delta_{j k}$ according to the REMBRANDT scale in Table 4 . The number of categories is rather small as human beings' linguistic capacity to describe the categories unambiguously in verbal terms is limited. ${ }^{19}$

Table 4. The REMBRANDT scale ${ }^{19}$

\begin{tabular}{lc}
\hline Comparative judgment & Gradation index $\delta_{j k}$ \\
\hline Very strong preference for $A_{k}$ over $A_{j}$ & -8 \\
Strong preference for $A_{k}$ over $A_{j}$ & -6 \\
Definite preference for $A_{k}$ over $A_{j}$ & -4 \\
Weak preference for $A_{k}$ over $A_{j}$ & -2 \\
Indifference & 0 \\
Weak preference for $A_{j}$ over $A_{k}$ & +2 \\
Definite preference for $A_{j}$ over $A_{k}$ & +4 \\
Strong preference for $A_{j}$ over $A_{k}$ & +6 \\
Very strong preference for $A_{j}$ over $A_{k}$ & +8 \\
\hline
\end{tabular}

Intermediate integer values can be assigned to $\delta_{j k}$ to express a hesitation between two adjacent categories. The gradation index $\delta_{j k}$ can be converted into a value on a geometric scale, characterised by a scale parameter $\gamma=\ln (1+\varepsilon)$, where $1+\varepsilon$ is the progression factor. Thus

$$
r_{j k}=\exp \left(\gamma \delta_{j k}\right), \quad j, k=1, \ldots, n
$$

is defined to be the numeric estimate of the preference ratio $V_{j} / V_{k}$. Although there is no unique scale of human judgment, a plausible value of $\gamma$ is $\ln (2)$ implying a geometric scale with the progression factor $2 .{ }^{14}$

There are five major, linguistically distinct categories in Table 3: indifference, weak, definite, strong and very strong. Moreover, there are four so-called threshold categories between them which can be used if the decision-makers are in-between the neighbouring qualifications. Lootsma ${ }^{19}$ shows that human beings follow the same pattern in many unrelated areas when they categorise an interval, e.g. certain ranges on the time axis and sound and light intensities. Normally three to five major categories are introduced and the progression factor $\exp (2 \gamma)=(1+\varepsilon)^{2}$ is roughly 4 , see Lootsma ${ }^{14,19}$. By the interpolation of threshold categories a more refined subdivision of the given interval is obtained. In that case there are six to nine categories and the progression factor $\exp (\gamma)=(1+\varepsilon)^{2}$ is 
roughly 2 ( $\gamma=\ln 2 \square 0.7$ ), which defines what Lootsma ${ }^{20}$ calls the natural REMBRANDT scale. In addition, Lootsma ${ }^{20}$ suggest that sensitivity analysis should be carried out with a short $(\gamma=0.5)$ and a long $(\gamma=1.0)$ geometric scale in the neighbourhood of the natural scale.

When determining criteria weights Lootsma ${ }^{19}$ finds the progression factor to be $\sqrt{ } 2$. The reason behind a lower progression factor may link to implicit trade-off consideration being more deliberate with criteria than is the case with scoring of alternatives.

In the psychophysical literature the issue of how human beings judge the relationship between two stimuli in a pair wise comparison on one single dimension was first treated 50 years ago by Torgerson. ${ }^{21}$ Torgerson observed that human beings perceive only one quantitative relation, but they estimate differences in subjective stimulus values when they are requested to express their judgement on a category scale with arithmetic progression (equidistant echelons) and they estimate ratios of subjective stimulus values when the proposed scale is geometric. Thus they interpret the relationship as it is required in the experiment. Which of the two interpretations is correct cannot empirically be decided, as they are alternative ways of saying the same thing.

This observation is easy to understand if it is assumed that the subjective stimulus values are not identically used in the two types of experiments. In the ratio experiment with a geometric scale human beings judge the ratio of two stimulus values. In the difference experiment with an arithmetic scale they do not judge the ratio itself but its order of magnitude, which is essentially a logarithm of the ratio. ${ }^{20}$

Veit $^{22}$ and Birnbaum ${ }^{23}$ confirmed Torgerson's observation that pair wise comparative judgment of two stimuli uses one operation only in both types of experiments. Moreover, if subtraction is assumed to be the underlying operation, then the ratio judgment is exponentially related to difference judgment.

\section{Applying the REMBRANDT technique on the case study}

To demonstrate the approach the four alternatives, A1, A2, A3 and A4, are compared in a pair wise way under the five criteria outlined in Table 3 . A decision conference approach as described in Barfod and Leleur ${ }^{24}$ and Phillips ${ }^{25}$ was used for the purpose of deriving preferences from the decision-makers involved in the decision process. Table $5-9$ shows the $\delta_{j k}$ matrices based on the decision-makers judgments as well as the transformed matrices and the row-wise geometric means.

Table 5. REMBRANDT calculations for C1: Impact on regional economics

\begin{tabular}{|c|c|c|c|c|c|c|c|c|c|}
\hline \multicolumn{5}{|c|}{ Pair wise comparisons $\left(\delta_{j k}\right)$} & \multicolumn{4}{|c|}{ Transformations $(\gamma=0.7)$} & \multirow{2}{*}{$\begin{array}{r}\text { Geo.mean } \\
\text { Score }\end{array}$} \\
\hline & A1 & A2 & A3 & A4 & A1 & A2 & A3 & A4 & \\
\hline A1 & 0 & 4 & -4 & -2 & 1 & 16 & 0.0625 & 0.25 & 0.71 \\
\hline A2 & -4 & 0 & -8 & -6 & 0.0625 & 1 & 0.0039 & 0.0156 & 0.04 \\
\hline A3 & 4 & 8 & 0 & 2 & 16 & 256 & 1 & 4 & 11.31 \\
\hline A4 & 2 & 6 & -2 & 0 & 4 & 64 & 0.25 & 1 & 2.83 \\
\hline
\end{tabular}


Table 6. REMBRANDT calculations for C2: Impact on ecology in sound

\begin{tabular}{rrrrr|rrrrr}
\hline \multicolumn{7}{c|}{ Pair wise comparisons $\left(\delta_{j k}\right)$} & \multicolumn{4}{c|}{ Transformations $(\gamma=0.7)$} & Geo.mean \\
\hline & A1 & A2 & A3 & A4 & A1 & A2 & A3 & A4 & Score \\
\hline A1 & 0 & 0 & 4 & 4 & 1 & 1 & 16 & 16 & 4.00 \\
A2 & 0 & 0 & 4 & 4 & 1 & 1 & 16 & 16 & 4.00 \\
A3 & -4 & -4 & 0 & 0 & 0.0625 & 0.0625 & 1 & 1 & 0.25 \\
A4 & -4 & -4 & 0 & 0 & 0.0625 & 0.0625 & 1 & 1 & 0.25 \\
\hline
\end{tabular}

Table 7. REMBRANDT calculations for C3: Impact on transport network and accessibility

\begin{tabular}{|c|c|c|c|c|c|c|c|c|c|}
\hline \multicolumn{5}{|c|}{ Pair wise comparisons $\left(\delta_{j k}\right)$} & \multicolumn{4}{|c|}{ Transformations $(\gamma=0.7)$} & \multirow{2}{*}{$\begin{array}{r}\text { Geo.mean } \\
\text { Score }\end{array}$} \\
\hline & A1 & $\mathrm{A} 2$ & A3 & $\mathrm{A} 4$ & A1 & $\mathrm{A} 2$ & A3 & A4 & \\
\hline A1 & 0 & 6 & -4 & -2 & 1 & 64 & 0.0625 & 0,25 & 1.00 \\
\hline A2 & -6 & 0 & -8 & -6 & 0.0156 & 1 & 0.0039 & 0.0156 & 0.03 \\
\hline A3 & 4 & 8 & 0 & 4 & 16 & 256 & 1 & 16 & 16.00 \\
\hline A4 & 2 & 6 & -4 & 0 & 4 & 64 & 0.0625 & 1 & 2.00 \\
\hline
\end{tabular}

Table 8. REMBRANDT calculations for C4: Impact on towns

\begin{tabular}{rrrrr|rrrrr}
\hline \multicolumn{5}{c}{ Pair wise comparisons $\left(\delta_{j k}\right)$} & \multicolumn{4}{c|}{ Transformations $(\gamma=0.7)$} & Geo.mean \\
\hline & A1 & A2 & A3 & A4 & A1 & A2 & A3 & A4 & Score \\
\hline A1 & 0 & -2 & 6 & 4 & 1 & 0.25 & 64 & 16 & 4.00 \\
A2 & 2 & 0 & 8 & 6 & 4 & 1 & 256 & 64 & 16.00 \\
A3 & -6 & -8 & 0 & -2 & 0.0156 & 0.0039 & 1 & 0.25 & 0.06 \\
A4 & -4 & -6 & 2 & 0 & 0.0625 & 0.0156 & 4 & 1 & 0.25 \\
\hline
\end{tabular}

Table 9. REMBRANDT calculations for C5: Robustness of feasibility

\begin{tabular}{|c|c|c|c|c|c|c|c|c|c|}
\hline \multicolumn{5}{|c|}{ Pair wise comparisons $\left(\delta_{j k}\right)$} & \multicolumn{4}{|c|}{ Transformations $(\gamma=0.7)$} & \multirow{2}{*}{$\begin{array}{r}\text { Geo.mean } \\
\text { Score }\end{array}$} \\
\hline & A1 & $\mathrm{A} 2$ & A3 & A4 & A1 & $\mathrm{A} 2$ & A3 & A4 & \\
\hline A1 & 0 & 6 & -4 & -6 & 1 & 64 & 0.0625 & 0.0156 & 0.50 \\
\hline A2 & -6 & 0 & -6 & -8 & 0.0156 & 1 & 0.0156 & 0.0039 & 0.03 \\
\hline A3 & 4 & 6 & 0 & -2 & 16 & 64 & 1 & 0.25 & 4.00 \\
\hline A4 & 6 & 8 & 2 & 0 & 64 & 256 & 4 & 1 & 16.00 \\
\hline
\end{tabular}

This is followed by pair wise comparisons of the five criteria in Table 10.

Table 10. REMBRANDT calculations for criteria weights

\begin{tabular}{|c|c|c|c|c|c|c|c|c|c|c|c|c|}
\hline \multicolumn{6}{|c|}{ Pair wise comparisons } & \multicolumn{5}{|c|}{ Transformations $(\gamma=0.35)$} & \multirow{2}{*}{$\begin{array}{c}\text { Geo. } \\
\text { mean } \\
\text { Score }\end{array}$} & \multirow[b]{2}{*}{ Norm. } \\
\hline & C1 & $\mathrm{C} 2$ & $\mathrm{C} 3$ & $\mathrm{C} 4$ & $\mathrm{C} 5$ & $\mathrm{C} 1$ & $\mathrm{C} 2$ & $\mathrm{C} 3$ & $\mathrm{C} 4$ & $\mathrm{C} 5$ & & \\
\hline $\mathrm{C} 1$ & 0 & 4 & -2 & 2 & -2 & 1 & 4 & 0.5 & 2 & 0.5 & 1.15 & 0.19 \\
\hline $\mathrm{C} 2$ & -4 & 0 & -4 & -3 & -4 & 0.25 & 1 & 0.25 & 0.3536 & 0.25 & 0.35 & 0.06 \\
\hline $\mathrm{C} 3$ & 2 & 4 & 0 & 3 & -2 & 2 & 4 & 1 & 2.8284 & 0,5 & 1.62 & 0.27 \\
\hline $\mathrm{C} 4$ & -2 & 3 & -3 & 0 & -3 & 0.5 & 2.8284 & 0.3536 & 1 & 0.3536 & 0.71 & 0.12 \\
\hline $\mathrm{C} 5$ & 2 & 4 & 2 & 3 & 0 & 2 & 4 & 2 & 2.8284 & 1 & 2.14 & 0.36 \\
\hline
\end{tabular}

The final scores for the alternatives are calculated using the multiplicative model and normalised: 
A1:

$$
0.71^{0.19} \cdot 4.00^{0.06} \cdot 1.00^{0.27} \cdot 4.00^{0.12} \cdot 0.50^{0.36} \quad=0.93 \sim 0.12
$$

A2: $\quad 0.04^{0.19} \cdot 4.00^{0.06} \cdot 0.03^{0.27} \cdot 16.00^{0.12} \cdot 0.03^{0.36}$

$=0.09 \sim 0.01$

A3: $\quad 11.31^{0.19} \cdot 0.25^{0.06} \cdot 16.00^{0.27} \cdot 0.06^{0.12} \cdot 4.00^{0.36}$

$=3.69 \sim 0.47$

A4: $\quad 2.83^{0.19} \cdot 0.25^{0.06} \cdot 2.00^{0.27} \cdot 0.25^{0.12} \cdot 16.00^{0.36}$

$=3.12 \sim 0.40$

By normalising the REMBRANDT scores above we arrive at the score-set: A1 $=0.12$; $\mathrm{A} 2=0.01 ; \mathrm{A} 3=0.47 ; \mathrm{A} 4=0.40$. If the same verbal responses instead had been processed using the AHP technique the scores would have been: $\mathrm{A} 1=0.15$; $\mathrm{A} 2=0.11$; $\mathrm{A} 3=0.38$; A4 $=0.36$, which is relatively close to the REMBRANDT scores, see Table 11. The basic observation here is that using the REMBRANDT technique the best performing alternatives seems to get an advantage due to the longer scale resulting in greater interval distance.

Table 11. Scores for the alternatives calculated using AHP and REMBRANDT applying different progression factors for the alternatives

\begin{tabular}{lcccc}
\hline & AHP & & REMBRANDT \\
& & $\gamma=0.5$ & 0.12 & $\gamma=1.0$ \\
\hline A1 & 0.15 & 0.19 & 0.01 & 0.04 \\
A2 & 0.11 & 0.04 & 0.47 & 0.01 \\
A3 & 0.38 & 0.41 & 0.40 & 0.52 \\
A4 & 0.36 & 0.36 & & 0.43 \\
\hline
\end{tabular}

As mentioned Lootsma ${ }^{20}$ suggests to conduct sensitivity analysis with $\gamma=0.5$ (progression factor on 1.6) and $\gamma=1.0$ (progression factor on 2.7) to test the robustness of the results. The outcome of this is also shown in Table 11.

To examine the sensitivity of the progression factor in a wider interval tests have been conducted varying the factor from 1 to 5 ( $\gamma$ values between 0.0 and 1.6), see Figure 2 . From this the important result that the rank order of the alternatives does not depend on the scale parameter $\gamma$ can be derived. 


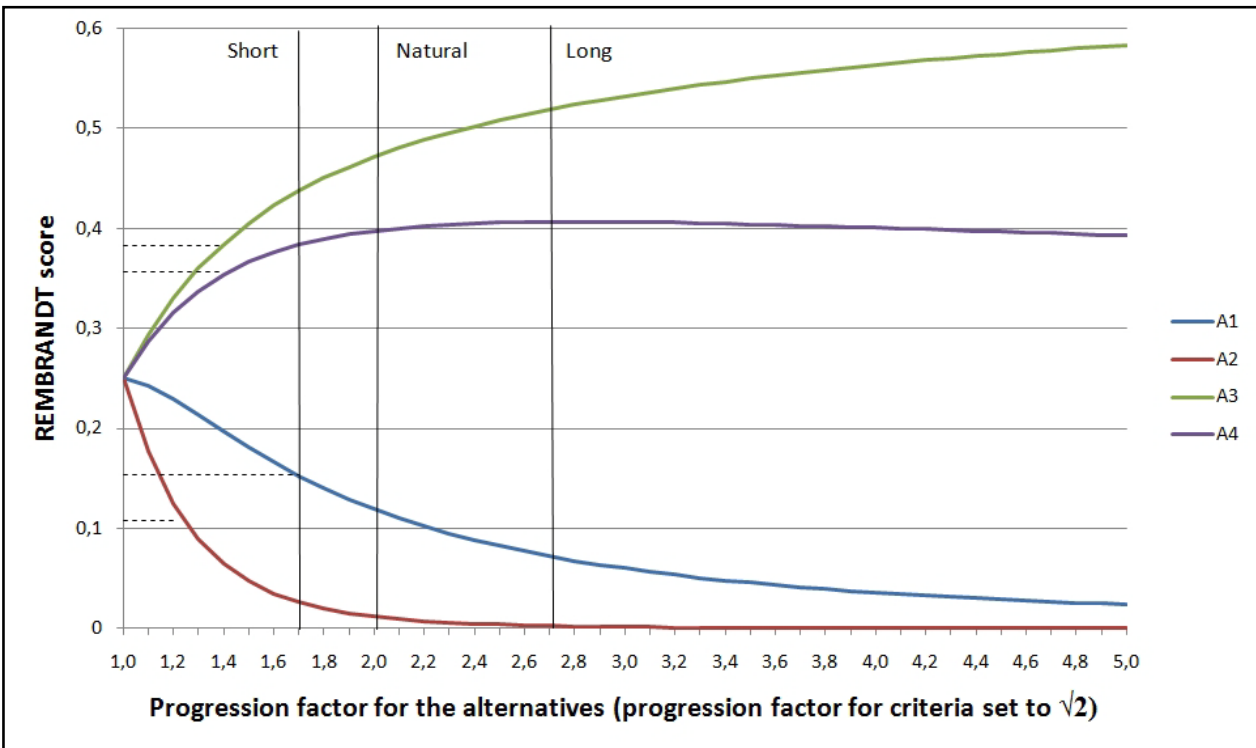

Figure 2. REMBRANDT scores at varying values of the progression factor for the alternatives. The vertical lines indicate the short, the natural and the long REMBRANDT scales proposed by Lootsma. ${ }^{20}$ The vertical dashed lines indicate the corresponding AHP scores (see Table 11).

It should be noted that the progression factor for the criteria weights is not varied in this sensitivity test as there is only proposed one particular geometric scale for this $(\gamma=0.35)$, not a variety of scales to quantify the gradations of comparative judgments. In practice the difference between pair wise comparisons at the first and second evaluation levels is small. There are conceptual differences between the evaluation levels, and this implies that the numerical values of the quantifiers are level dependent. ${ }^{20}$

\section{Discussion of results}

Observing Figure 2 it seems reasonable that the progression factor should not exceed 2.7, as indicated by Lootsma ${ }^{20}$, by much. Higher factors will increase then span between the worst performing and the best performing alternatives more than seems appropriate. Similarly, progression factors close to 1 do not seem appropriate as the segregation between both alternatives and criteria will be very narrow leading to almost identical scores. In fact, the interval proposed by Lootsma ${ }^{20}$ seems intuitively appropriate with a short, a natural and a long scale. The calculations clearly illustrate that the ratio of two final scores is scale dependent, even under conditions which guarantee that it is not affected by the addition or deletion of alternatives.

As mentioned, there is only proposed one geometric scale for the criteria weights. However, as this scale with the progression fatoorseems to be a result of the mathematics behind the method ${ }^{15}$ it could also be interesting to conduct a sensitivity analysis on this. In Figure 3 the progression factor for the alternative is fixed to 2, while 
the progression factor for the criteria is varied in an interval from 1 to 2.3 (as no changes in rankings takes place after this point).

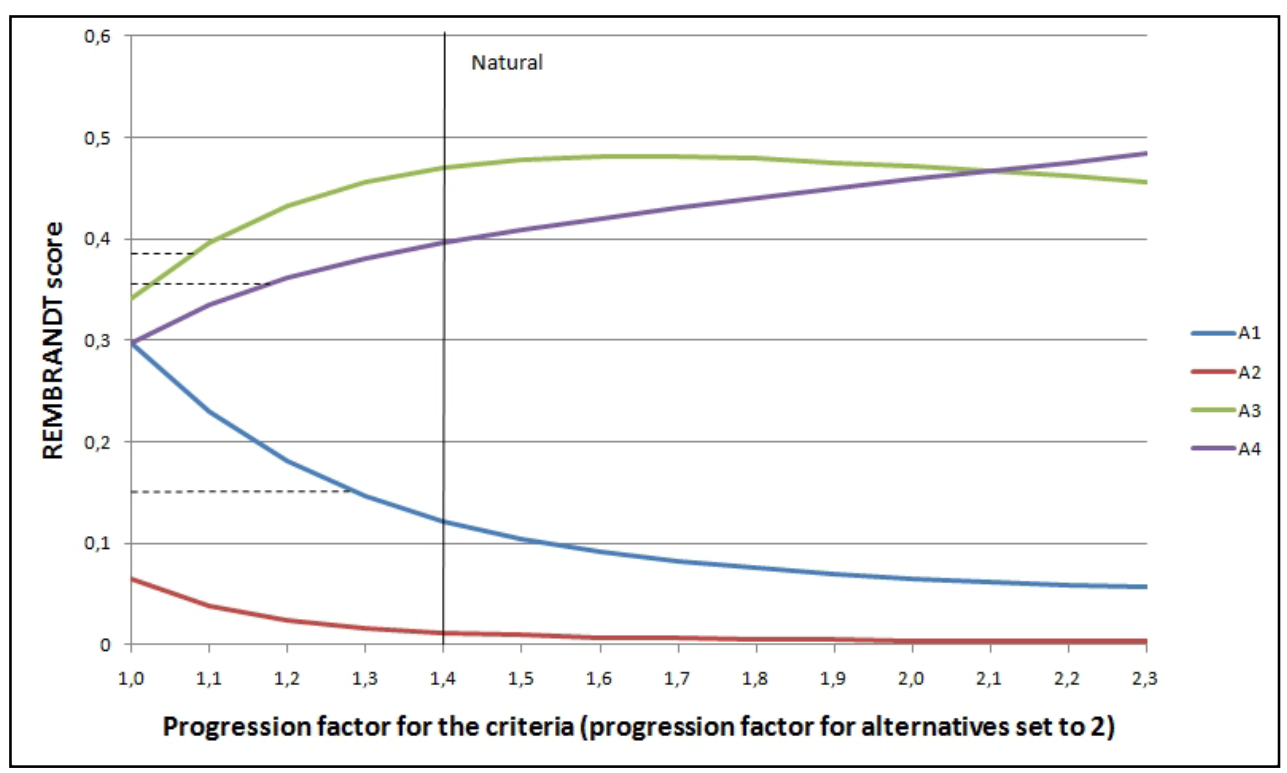

Figure 3. REMBRANDT scores at varying values of the progression factor for the criteria. The vertical line indicates the natural REMBRANDT scale with the progression fadtor The progression factor for the alternatives is fixed to 2. The vertical dashed lines indicate the corresponding AHP scores (see Table 11).

The results in Figure 3 clearly show that the rank order of the alternatives does depend on the scale parameter $\gamma$ for the criteria. This makes good sense and it can be noted that the rank reversal which takes place between A3 and A4 at a progression factor on approximately 2.1 is caused by the fact that the weight for $\mathrm{C} 5$ (the criterion with the highest weight) becomes very dominant at high progression factors. Hence, the remaining criteria will move towards exclusion from the analysis, and the alternative which scores the best under C5 (A4 in this case) will be the most attractive. A3 is in this respect only the second highest scoring alternative under C5 (see Table 9). Thus, a progression factor for the criteria that exceeds $\sqrt{2}$ will not be appropriate in practical use. 


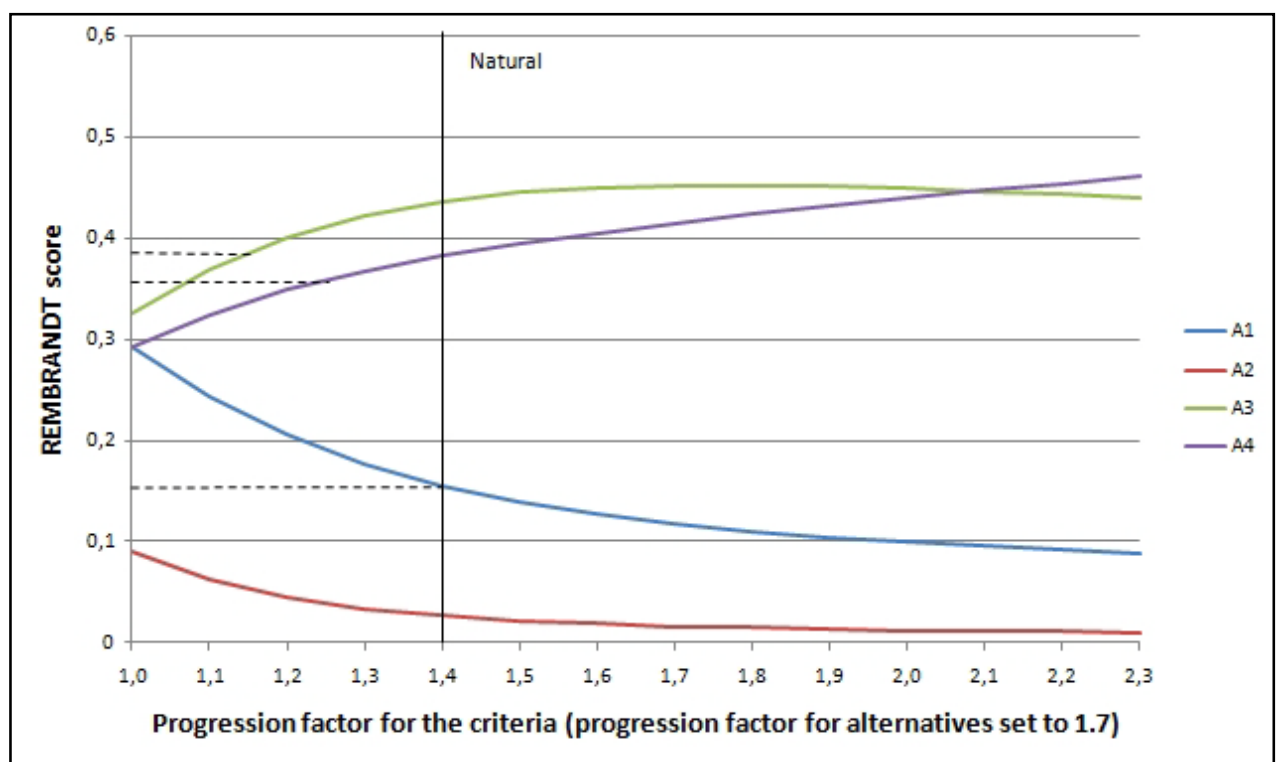

Figure 4. REMBRANDT scores at varying values of the progression factor for the criteria. The vertical line indicates the natural REMBRANDT scale with the progression fadtar The progre ssion factor for the alternatives is now fixed to 1.7 (the short scale). The vertical dashed lines indicate the corresponding AHP scores (see Table 11).

The results implies that a modified version of REMBRANDT could make use of the progression factors 1.7 and 1.3 for alternatives and criteria respectively in order to obtain results closer in line with the results from the original AHP.

In order to test this argument another case example, which concerns four alternatives for a railway line assessed under eight criteria, is examined, see Table 12. The case is described in details in Barfod et al. ${ }^{26}$

Table 12. Scores for the alternatives in Barfod et al. ${ }^{26}$ calculated using AHP and REMBRANDT applying different progression factors.

\begin{tabular}{lccccc}
\hline Alternative & AHP & \multicolumn{4}{c}{ REMBRANDT } \\
& & $\begin{array}{c}\text { A-prog. } 2 \\
\text { C-prog. } \sqrt{2}\end{array}$ & $\begin{array}{c}\text { A-prog. } 1.7 \\
\text { C-prog. } \sqrt{2}\end{array}$ & $\begin{array}{c}\text { A-prog. } 1.7 \\
\text { C-prog. } 1.3\end{array}$ & A-prog. 1.7 \\
C-prog. 1.6
\end{tabular}

The results in Table 12 are not in support of the previous results that argued for a lowering of the criteria progression factor. This might very well be due to a higher number of criteria in the assessment. However, the results still imply that a lowering of the alternative progression factor to 1.7 seems reasonable. 
One more case study featuring four alternatives for a fixed link assessed under four criteria is examined in Table 13 to test the robustness of the arguments. The case is described in details in Barfod et al. ${ }^{27}$

Table 13. Scores for the alternatives in Barfod et al. ${ }^{27}$ calculated using AHP and REMBRANDT applying different progression factors

\begin{tabular}{lccccc}
\hline Alternative & AHP & \multicolumn{2}{c}{ REMBRANDT } \\
& & A-prog. 2 & A-prog. 1.7 & A-prog. 1.7 & A-prog. 1.7 \\
& & C-prog. $\sqrt{ } 2$ & C-prog. $\sqrt{2}$ & C-prog. 1.3 & C-prog. 1.6 \\
\hline HL & 0.44 & 0.69 & 0.68 & 0.60 & 0.76 \\
ST & 0.23 & 0.15 & 0.16 & 0.18 & 0.14 \\
LT & 0.18 & 0.07 & 0.06 & 0.10 & 0.03 \\
UP & 0.15 & 0.09 & 0.09 & 0.12 & 0.06 \\
\hline
\end{tabular}

The REMBRANDT results in Table 13 differ much more from the original AHP results than has been the case with the two previous examined studies. The difference concerns both the size of the scores and the implied ranking, see the ranking of the alternatives on level three and four. However, the results are in line with the previous results in the sense that a lower progression factor for the alternatives seems reasonable.

Finally, a forth case study is examined. The case, which is described in details in Barfod $^{28}$, concerns five alternatives for bike projects assessed under five criteria. Table 14 depicts the results derived.

Table 14. Scores for the alternatives in $\operatorname{Barfod}^{28}$ calculated using AHP and REMBRANDT applying different progression factors

\begin{tabular}{lccccc}
\hline Alternative & AHP & \multicolumn{4}{c}{ REMBRANDT } \\
& & $\begin{array}{c}\text { A-prog. } 2 \\
\text { C-prog. } \sqrt{ } 2\end{array}$ & $\begin{array}{c}\text { A-prog. } 1.7 \\
\text { C-prog. } \sqrt{2}\end{array}$ & $\begin{array}{c}\text { A-prog. 1.7 } \\
\text { C-prog. 1.3 }\end{array}$ & $\begin{array}{c}\text { A-prog. } 1.7 \\
\text { C-prog. } 1.6\end{array}$ \\
\hline ID1 & 0.06 & 0.04 & 0.06 & 0.05 & 0.05 \\
ID2 & 0.16 & 0.14 & 0.16 & 0.17 & 0.16 \\
ID3 & 0.19 & 0.19 & 0.20 & 0.20 & 0.20 \\
ID4 & 0.38 & 0.45 & 0.39 & 0.39 & 0.40 \\
ID5 & 0.21 & 0.18 & 0.19 & 0.19 & 0.19 \\
\hline
\end{tabular}

The results in Table 14 show almost insignificant sensitivity towards the size of the progression factors. This may be caused by the fact that the ratifying group doing the comparisons consisted of government officers and that the decision problem was of a politically sensitive nature. For this reason the group tended to apply the semantic scale with highest precaution using only the lower values on the scale. Hence, the segregation between the alternatives is low no matter which of the approaches, AHP or REMBRANDT, is applied. However, observing Table 14 a progression factor for the alternatives on 1.7 seems most reasonable.

Overall, the results of the different case studies show that the REMBRANDT technique moderates the valuation of "extreme" versus "balanced" alternatives. In the additive AHP it may be mathematically impossible for "middle of the road" alternatives to achieve the highest overall ratings. This makes little sense from a practical viewpoint. 
The multiplicative version ensures due consideration of "middle of the road" nondominated alternatives when these are assessed with alternatives that are extremely attractive with respect to some criteria and extremely un-attractive with regard to other ones. Thus, in addition to mathematical considerations (ratio scale property) there appears to be important behavioural motivation for using the REMBRANDT technique.

In practice "middle of the road" alternatives may very well be the most preferred ones; however, the flexibility of the REMBRANDT technique with varying $\gamma$-values appears to offer the decision-makers an attractive modelling framework. Previous studies of the REMBRANDT technique, such as Lootsma ${ }^{20}$ and Stam and Silva ${ }^{29}$, have implicitly assumed that the preference ratings are the geometric means of pair wise comparisons exhibiting constant returns to scale. This is a requirement which may be reasonable in many decision problems. ${ }^{29}$ Nevertheless, allowing for a flexible value of $\gamma$ allows for a meaningful analysis of situations where increasing or decreasing returns to scale are appropriate.

\section{Conclusion}

This paper has examined a DSS for the appraisal of complex decision problems using MCDA. More specifically the multiplicative version of AHP, namely the REMBRANDT technique, has been examined with regard to the issue of the progression factor when transforming decision-makers verbal responses to the geometric scale. AHP was first introduced by Saaty ${ }^{5}$ based on an additive value function model. Several improvements of the technique have been made over the years, e.g. the introduction of the geometric mean method by Barzilai et al. ${ }^{11}$ With the REMBRANDT technique (based on a multiplicative utility function) by Lootsma ${ }^{14}$ a serious off-spring alternative to the original AHP was introduced.

Both the original AHP and the REMBRANDT techniques can be considered as effective DSSs for group decision making. The additive AHP allows a multi-level hierarchy; however, this is hardly an advantage as decision-makers tend to insist on a one-level hierarchy as this seems more intuitive. Moreover, as noted in Section 5, the final scores calculated by the two versions of AHP do not strongly diverge. However, the aggregation rule used by REMBRANDT seems appropriate as it fits the exponential form of the input given by the decision-makers.

In the ease of use the two versions are very similar as they need the same type of input and provide the same type of output. The original additive AHP has one scale only and ignores scale dependence, whereas the REMBRANDT technique, based on a one parametric class of geometric scales, yields a scale-independent rank order of the final scores and avoids rank reversal in some notorious cases where this phenomenon is not expected to occur. Seen from a theoretical viewpoint the geometric least squares method of REMBRANDT is preferable. However, in practice it does not seem to make much of a difference which method is selected.

Based on the case studies it can be recommended to conduct sensitivity analysis applying different progression factors on both the alternatives scores level and the criteria 
weights level. The rank order of the alternatives does not depend on the scale parameter $\gamma$ when this is changed for the alternatives score level. However, it can be concluded that the scale parameter should not exceed the long scale (a progression factor on 2.7) by much as the span between the scores becomes inappropriately large. As opposed to this the rank order of alternatives are very sensitive towards changes in the progression factor on the criteria weight level. Therefore it can be recommended that a progression factor on 1.7 (the short scale) can be applied at the alternatives score level while the criteria weight level should continue to make use of a progression factor om $/ 2$ if it is desirable to arrive at results closer in line with the original AHP.

Future research within this area should concentrate on studying the further properties of the REMBRANDT technique seen from both a theoretical and empirical point of view. The attractiveness of the multiplicative version in practice compared to the additive version will in some cases depend on the decision problem. Nevertheless, the multiplicative version with variable $\gamma$-values is consistent with well-grounded postulates of human decision making which makes it attractive to apply when approaching complex appraisal problems by using multiple pair wise comparisons.

\section{References}

1. L. A. Larsen and B. Z. Skovgaard, Appraisal of alternatives concerning a fixed link between Elsinore and Helsingborg (Master thesis, Department of Transport, Technical University of Denmark, Denmark, 2010).

2. Danish Ministry of Transport, Manual for socio-economic analysis - applied methodology in the transport sector (Copenhagen, 2003) (in Danish).

3. K. B. Salling, S. Leleur, and B. Z. Skougaard, Reference Scenario Forecasting: A new approach to Transport Project Assessment, Proc. 10th World Conf. on Transport Research (WCTR), Lisbon, 2010.

4. K. B. Salling and S. Leleur, Modelling of Transport Project Uncertainties: Risk Assessment and Scenario Analysis, accepted for publication in European Journal of Transport Infrastructure Research (Open Access, TUDelft, accepted).

5. T. L. Saaty, Scenarios and priorities in transport planning: Application to the Sudan, Transport Research 11 (1977) 343-350.

6. T. L. Saaty and M. Sagir, Extending the measurement of tangibles to intangibles, International Journal of Information Technology \& Decision Making 8 (2009) 7-27.

7. F. Zahedi, The analytic hierarchy process - a survey of the method and its applications, Interfaces 16 (1986) 96-108.

8. V. Belton, A comparison of analytic hierarchy process and a simple multi-attribute value function, European Journal of Operational Research 26 (1986) 7-21.

9. T. J. Stewart, A critical survey on the status of multi-criteria decision making theory and practice, Omega 20 (1992) 569-586.

10. P. Korhonen and H. Topdagi, Performance of the AHP in comparison of gains and losses, Mathematical and Computer Modelling 37 (2003) 757-766.

11. J. Barzilai, W. Cook, and B. Golany, Consistent weights for judgement matrices of the relative importance for alternatives, Operations Research Letters 6:3 (1987) 131-134.

12. J. Barzilai and B. Golany, An axiomatic framework for aggregating weights and weight-ratio matrices. Proc. Sec. Int. Symp. AHP, Pittsburgh, 1991, pp. 59-70. 
13. J. Barzilai, On the use of the eigenvector in the AHP. Proc. Int. Conf. MCDM, Tapei, 1992, pp. 291-300.

14. F. A. Lootsma, The REMBRANDT system for multi-criteria decision analysis via pair wise comparisons or direct rating (Report 92-05, Faculteit der Technische Wiskunde en Informatica, Delft University of Technology, Netherlands, 1992).

15. D. L. Olson, G. Fliedner, and K. Currie, Comparison of the REMBRANDT system with analytic hierarchy process, European Journal of Operational Research 82 (1995) 522-539.

16. R. Ramanathan, Stochastic decision making using multiplicative AHP, European Journal of Operational Research 97 (1997) 543-549.

17. D. L. Olson, Decision Aids for Selection Problems (Springer-Verlag, 1996).

18. S. Zahir, Eliciting ratio preferences for the analytic hierarchy process with visual interfaces: A new mode of preference measurement, International Journal of Information Technology \& Decision Making 5 (2006) 245-261.

19. F. A. Lootsma, Multi-criteria decision analysis via ratio and difference judgement (Kluwer Academic Publishers, 1999).

20. F. A. Lootsma, Scale sensitivity in the multiplicative AHP and SMART, Journal of MultiCriteria Decision Analysis 2 (1993) 87-110.

21. W. S. Torgerson, Distances and ratios in psycho-physical scaling, Acta Psychological 19 (1961) 201-205.

22. C. T. Veit, Ratio and subtractive processes in psycho-physical judgment, Journal of Exp. Psychol: Gen 107 (1978) 81-107.

23. M. H. Birnbaum, Controversies in psychological measurement, Social attitudes and psycophysical measurement, eds. B. Wegener Hillsdale (1982), pp. 401-485.

24. M. B. Barfod and S. Leleur, Customised DSS and decision conferences, Proc. 13th EWGT meeting, Padua, 2009 (University of Padua, Italy, 2009).

25. L. D. Phillips, Decision conferencing, Advances in decision analysis - from foundations to applications, eds. W. Edwards, R. F. Miles, and D. von Winterfeldt (Cambridge University Press, 2007), pp. 375-400.

26. M. B. Barfod, A. V. Jensen, and S. Leleur, Examination of Decision Support Systems for Composite CBA \& MCA Assessments of Transport Infrastructure Projects, New State of MCDM in the 21st Century, eds. Y. Shi, S. Wang, G. Kou, and J. Wallenius (Lecture Notes in Economics and Mathematical Systems 648, Springer, 2011a), pp. 167-176.

27. M. B. Barfod, K. B. Salling, and S. Leleur, Composite Decision Support by Combining Costbenefit and Multi-criteria Decision Analysis, Decision Support Systems 51 (2011b) 167-175.

28. M. B. Barfod, Structuring and assessing large and complex decision problems using MCDA, under review for European Journal of Operational Research (forthcoming).

29. A. Stam and A. P. D. Silva, On multiplicative priority rating methods for the AHP, European Journal of Operational Research 145 (2003) 92-108. 